\title{
The Lifetime Prevalence and Socio-Demographic Correlations of Major Depressive Episodes in Tunisian Primary Care Settings
}

Ahmed Souhail Bannour, Mohamed Wassim Krir ${ }^{*}$, Amel Braham, Selma Ben Nasr and Bechir Ben Hadj Ali

Farhat Hached Hospital, Sousse, Tunisia

"Corresponding author: Mohamed Wassim Krir, Farhat Hached Hospital Psychiatry, Ibn Jazzar Street, Sousse, 4000, Tunisia, Tel: +21653151411; FAX: +21673223702; E-mail: wassim.krir@outlook.com

Received Date: November 5, 2014, Accepted Date: December 15, 2014, Published Date: December 23, 2014

Copyright: ( 2015 , Mohamed Wassim Krir, et al., This is an open-access article distributed under the terms of the Creative Commons Attribution License, which permits unrestricted use, distribution, and reproduction in any medium, provided the original author and source are credited.

\begin{abstract}
Objective: Planning prevention and treatment programs for depression should be based on the study of the epidemiological profile of depression in the region. The aim of this study was to assess the lifetime prevalence and socio-demographic correlations of Major Depressive Episodes (MDE) among patients consulting in primary care settings.

Method: This is an epidemiological study involving patients consulting a general practitioner in Tunisia during a 12 months period. The study was carried using a questionnaire assessing the socio-demographic characteristics of patients and the E section of CIDI 2.1 translated and validated in Tunisian dialect.

Results: The number of included patients was 1309. The lifetime prevalence of MDE was $11 \%$ and their frequency was significantly correlated with female sex and divorced status.

Conclusion: These results can be helpful in developing an epidemiological profile of depression in Tunisian socio-cultural context and highlight the need to provide training on depressive disorders to caregivers in the primary care settings.
\end{abstract}

Keywords: Major depressive episode; Prevalence; Primary care; CIDI; Tunisia

\section{Introduction}

Depressive disorders are among the most common disorders in the general population. A meta-analysis of estimates from 17 studies in the general population found that the prevalence of depression over one year ranged from 3 to $10 \%$ with a median of $6.9 \%$. The economic cost of depressive disorders is also high, in fact, it was estimated to be comparable to the cost of diabetes or heart diseases. In addition, depression induces a significant decrease in labor productivity and by 2020 , it will be the second leading cause of disability in the world. The severity of depression is also due to its mortality, since nearly $70 \%$ of people who die by suicide suffer from depression, often undiagnosed or untreated [1-6].

Limiting this impact is nevertheless possible through the planning of prevention and treatment programs for depression. These programs are based on public information and on improving screening and management of depression especially in general practice. In fact, depression is gradually becoming a social issue and a challenge for general practice. According to the study DEPRES, more than two out of five persons with depression have not seen a doctor, and when they seek for medical advice, they turn more frequently to their general practioner than to a psychiatrist [7].

Planning prevention and treatment programs for depression must take into account the sociocultural context and should then be based on the study of the epidemiological profile of depression in the region. Given the absence of published studies on this profile in Tunisia, this work aimed to assess the lifetime prevalence and socio-demographic correlations of Major Depressive Episodes (MDE) among patients consulting in Tunisian primary care settings.

\section{Methods}

This is a non-interventional descriptive epidemiological study.

\section{Study Population}

\section{Target population}

This study was conducted in different regions of Tunisia and involved patients who consulted a general practitioner for any reason from 21 July 2009 (first patient enrolled) to 15 June 2010 (last patient completed).

\section{Sample size}

The sample size was calculated so that it can describe the profile of patients diagnosed as having a MDE. A minimum level of MDE lifetime prevalence of $8 \%$ was considered $(\mathrm{p}=0.08)$ with an accuracy $(\mathrm{i})$ equal to $1 / 5$. Using the formula $N=1.96^{2} \mathrm{p}(1-\mathrm{p}) / \mathrm{i}$, we found that 1150 patients had to be recruited [2]

\section{Selection criteria}

The inclusion criteria were an age $\geq 18$ years and the ability to answer the questionnaire. This ability was evaluated by the interviewer and was based on two criteria: understanding of the Tunisian dialect 
Page 2 of 6

and not having a severe cognitive impairment. Patients were excluded from the study if they were considered as a threat for the doctor security (substance abuse, agitation, aggressiveness) or if their health state was evaluated as an emergency.

\section{Assessment instruments}

The study was carried using a questionnaire divided into two parts: The first part concerned socio-demographic characteristics (sex, age, marital status, place of residence, educational level and professional activity) and the second part consisted of the "E section" of the Composite International Diagnostic Interview (CIDI) version 2.1. We used this interview because its "E section" about depressive disorders is translated and validated in Tunisian dialect. After data entry in ishell program, MDE diagnosis was obtained according to ICD-10 criteria [8].

\section{Interviewers}

This study was proposed to 80 general practitioners randomly selected, each one having to administer the test to at least 15 consultants which would give 1200 patients. 62 of them agreed to participate and 57 completed the study. All participants received training on: the history of the CIDI, epidemiological benefit of using the CIDI, how to use the CIDI and the modalities of the investigation. This training was provided using journals' articles, the instructions' manual of the CIDI and the research protocol. Participants were divided into three groups and each group received training for a halfday. At the end of training, at least two interviews were carried among participants themselves, and then each participant had to carry one or more interviews with a family member, a co-worker or a consultant. After each week, data of all participants were collected by the research team and a meeting took place in order to discuss the difficulties encountered by the participants.

\section{Ethical considerations}

Patients were recruited only after obtaining their free and informed consent. The anonymity of patients and the confidentiality were respected. Whenever a diagnosis of MDE was found during the evaluation, a specific follow-up was proposed.

\section{Results}

A total number of 7406 patients consulted during the screening days and 1309 of them were included in the study.

Socio-demographic characteristics of patients (Table 1)

\begin{tabular}{|l|l|l|l|}
\hline parameters & & number & percentage \\
\hline sex & male & 605 & $46.2 \%$ \\
\hline & female & 704 & $53.8 \%$ \\
\hline age & $<25$ years & 119 & $9.1 \%$ \\
\hline & $25-34$ years & 300 & $22.9 \%$ \\
\hline & $35-44$ years & 343 & $26.2 \%$ \\
\hline & $45-54$ years & 270 & $20.6 \%$ \\
\hline & $55-64$ years & 161 & $12.3 \%$ \\
\hline
\end{tabular}

\begin{tabular}{|c|c|c|c|}
\hline & $65-74$ years & 89 & $6.8 \%$ \\
\hline & $\geq 75$ years & 27 & $2.1 \%$ \\
\hline \multirow[t]{4}{*}{ marital status } & single & 296 & $22.6 \%$ \\
\hline & married & 910 & $69.5 \%$ \\
\hline & divorced & 39 & $3.0 \%$ \\
\hline & widow & 64 & $4.9 \%$ \\
\hline \multirow[t]{2}{*}{ place of residence } & urban & 1144 & $87.4 \%$ \\
\hline & rural & 165 & $12.6 \%$ \\
\hline \multirow[t]{4}{*}{ educational level } & illiterate & 107 & $8.2 \%$ \\
\hline & Primary school & 275 & $21.0 \%$ \\
\hline & Secondary school & 531 & $40.6 \%$ \\
\hline & University & 396 & $30.3 \%$ \\
\hline \multirow[t]{6}{*}{ professional activity } & $\begin{array}{l}\text { independent } \\
\text { profession }\end{array}$ & 223 & $17.0 \%$ \\
\hline & senior manager & 177 & $13.5 \%$ \\
\hline & middle manager & 174 & $13.3 \%$ \\
\hline & employee & 105 & $8.0 \%$ \\
\hline & worker & 142 & $10.8 \%$ \\
\hline & not active & 488 & $37.3 \%$ \\
\hline
\end{tabular}

Table 1: Socio-demographic characteristics of patients

The age of patients was $44.3 \pm 14.5$ years and they were female in $53.8 \%$ of cases. A married status was found in $69.5 \%$ of cases and an urban residence in $87.4 \%$ of cases. The educational level was secondary school in $40.6 \%$ of cases and $37.3 \%$ of patients were without professional activity.

Lifetime prevalence and socio-demographic correlations of MDE among patients (Table 2).

The total number of MDE was 144 and concerned $11 \%$ of patients. MDE were significantly more frequent in women than in men ( $p$ $<0.001)$ and their prevalence was significantly higher among divorced patients $(\mathrm{p}<0.001)$. The lifetime prevalence of MDE was not significantly correlated with age, place of residence, educational level or professional activity.

\begin{tabular}{|l|l|l|l|l|}
\hline parameters & & $\begin{array}{l}\text { number of } \\
\text { MDE }\end{array}$ & percentage & $\mathbf{p}$ \\
\hline sex & male & 42 & $6.9 \%$ & $\begin{array}{l}< \\
0.001\end{array}$ \\
\hline & female & 102 & $14.5 \%$ & \\
\hline age & $<25$ years & 13 & $10.9 \%$ & NS \\
\hline & $25-34$ years & 36 & $12.0 \%$ & \\
\hline & $35-44$ years & 48 & $14.0 \%$ & \\
\hline
\end{tabular}


Page 3 of 6

\begin{tabular}{|c|c|c|c|c|}
\hline & $45-54$ years & 23 & $8.5 \%$ & \\
\hline & $55-64$ years & 15 & $9.3 \%$ & \\
\hline & $65-74$ years & 5 & $5.6 \%$ & \\
\hline & $\geq 75$ years & 4 & $14.8 \%$ & \\
\hline \multirow[t]{4}{*}{ marital status } & single & 38 & $12.8 \%$ & $\begin{array}{l}< \\
0.001\end{array}$ \\
\hline & married & 86 & $9.5 \%$ & \\
\hline & divorced & 13 & $33.3 \%$ & \\
\hline & widow & 7 & $10.9 \%$ & \\
\hline \multirow[t]{2}{*}{ place of residence } & urban & 128 & $11.2 \%$ & NS \\
\hline & rural & 16 & $9.7 \%$ & \\
\hline \multirow[t]{4}{*}{ educational level } & illiterate & 13 & $12.1 \%$ & NS \\
\hline & $\begin{array}{l}\text { Primary } \\
\text { school }\end{array}$ & 29 & $10.5 \%$ & \\
\hline & $\begin{array}{l}\text { Secondary } \\
\text { school }\end{array}$ & 63 & $11.9 \%$ & \\
\hline & University & 39 & $9.8 \%$ & \\
\hline \multirow[t]{6}{*}{ professional activity } & $\begin{array}{l}\text { independent } \\
\text { profession }\end{array}$ & 13 & $5.8 \%$ & NS \\
\hline & $\begin{array}{l}\text { senior } \\
\text { manager }\end{array}$ & 19 & $10.7 \%$ & \\
\hline & $\begin{array}{l}\text { middle } \\
\text { manager }\end{array}$ & 18 & $10.3 \%$ & \\
\hline & employee & 10 & $9.5 \%$ & \\
\hline & worker & 19 & $13.4 \%$ & \\
\hline & not active & 65 & $13.3 \%$ & \\
\hline
\end{tabular}

Table 2: Lifetime prevalence and socio-demographic correlations of MDE among patients

\section{Discussion}

Drawing up an epidemiological profile for major depressive disorder allows planning prevention and treatment programs adapted to the study area. Given the absence of published data on this profile in Tunisia, this study aimed to assess the lifetime prevalence and sociodemographic correlations of MDE among patients consulting in Tunisian primary care settings. A survey of 1309 patients during one year was conducted. The E section of the CIDI 2.1 translated and validated in Tunisian dialect was used for the diagnosis of MDE. The average age of patients was $44 \pm 14.5$ years with predominance of female sex, urban origin and married status. The lifetime prevalence of MDE was $11 \%$. Their frequency was significantly correlated with female sex and divorced status. There was no significant difference in terms of age, place of residence, educational level and professional activity.

\section{Lifetime Prevalence of MDE}

The lifetime prevalence of MDE in general medical practice in this study was $11 \%$. Comparing this result with those of epidemiological studies in different countries around the world must take into account differences in methodology, particularly concerning the study population and the assessment tool.

In fact, several epidemiological studies have also used CIDI for screening MDE in the general population: the Canadian Community Health Survey, which was the first national study in Canada to use a full version of the CIDI, found a MDE lifetime prevalence of $12.2 \%$. However, other studies have found higher rates such as $29.6 \%$ in Montreal. In the USA, The National Comorbidity Survey (NCS) conducted between 1990 and 1992 on a sample of 8098 people found a MDE lifetime prevalence of $14.9 \%$. The National Comorbidity SurveyReplication (NCS-R) conducted between 2001 and 2002 on a sample of 9090 people found a MDE lifetime prevalence of $16.2 \%$. In Latin America, lower rates were described such as $4.6 \%$ in a Puerto Rican national survey and $10 \%$ in a Brazilian study. In the European Study of the Epidemiology of Mental Disorders (ESEMeD), the WMH-CIDI was used for a sample of 21425 people from six European countries (Belgium, France, Germany, Italy, the Netherlands and Spain) and the MDE lifetime prevalence was $12.8 \%$. The Netherlands Mental Health Survey and Incidence Study (NEMESIS) in which 7076 people were interviewed, the CIDI was used and the MDE lifetime prevalence was $15.4 \%$. In a Norwegian psychiatric epidemiological study using a random sample of 2066 subjects found a MDE lifetime prevalence of 17.8\%. Few studies in Africa and Asia have been carried with the CIDI and the MDE prevalence in these studies were lower ranging from 6.2\% in United Arab Emirates to 2.7\% in Ethiopia and 3\% in Japan [9-20].

Additional epidemiological studies have used other assessment instruments for MDE than the CIDI, such as the Primary Care Evaluation of Mental Disorders Patient Questionnaire (PRIME-MD PQ): a Belgian study concerning 2316 randomly selected patients reported a MDE lifetime prevalence of $13.9 \%$, a spnish study estimated the lifetime prevalence of MDE at $26.5 \%$ and an american study found a lifetime prevalence of $18.9 \%$. Other studies have used the Mini International Neuropsychiatric Interview (MINI): In France, the survey "Santé Mentale en Population Générale » (SMPG), estimated MDE lifetime prevalence at 5.6\%6 and in Uganda a lifetime prevalence of $5.4 \%$ was found. Other studies have used the Patient Health Questionnaire (PHQ): the National Health and Nutrition Examination Survey (NHANES) conducted from 2005 to 2008 in the United States which found a lifetime prevalence of $16.2 \%$, while other studies have found lower prevalence such as $9 \%$ in Germany and $9.1 \%$ in France [21-26].

This discrepancy between the results could be explained by the differences between samples in terms of size and characteristics, the use of different assessment instruments and the particularities of each region.

\section{Factors Associated to MDE}

\section{Sex}

In this study, MDE were significantly more frequent in women than in men. In fact, most of studies have reported that women were more likely than men to be depressed. In France, these findings were highlighted through the surveys Health Barometer (HB) and SMPG. 
Similar results were found by surveys carried in Australia, New Zealand, Saudi Arabia, Ethiopia, Taiwan, Puerto Rico, and Brazil $[6,13,14,19,27-33]$.

This difference between the sexes in rates of depression would appear at the age of puberty and subsides after menopause which highlights the complex interactions between biological, psychological and socio-cultural factors. Alcoholism, which is more common in men, is in some cases a depressive equivalent and a different mode of expression. It can be a way to escape from the epidemiological studies on depression. Then Zurich study defined the number of symptoms to diagnose depression as 5 out of 8 in women and 3 out of 8 in men. Despite this adjustment of the diagnostic criteria, the prevalence of depression remained lower in men compared to women. Another study comparing results from the Zurich Study and the NCS-R found that the gender differences were due to the somatic symptoms rather than the number of symptoms and were greater for somatic than for atypical depression [34-37].

\section{Age}

The prevalence of MDE in this study was not significantly correlated with age. The same result has been reported by other studies in Japan, in Ethiopia and in South Korea. However, several other studies have reported different results: a study conducted in Liverpool, a French study and the HUNT study found that MDE were more common in patients older than 65 years. On the contrary, in the $\mathrm{HB}$ study, the authors concluded that patients aged of 15-24 years would be more vulnerable to depression than those over 65 years. [19,29,38-42]. In a Canadian study, it was found that young people had more depression with $5 \%$ of patients younger than 25 years having a MDE compared to only $1.9 \%$ over the age of 65 years. This decrease in the lifetime prevalence of major depressive disorders in older adults was explained by a more psychological stability after 65 years and by an age-related difference in the lifetime prevalence of sub threshold hypomania. In addition, depression often goes unnoticed in the elderly, indeed, some symptoms such as loss of motivation, fatigue and isolation can be attributed to aging. Furthermore, some measurement tools such as the CIDI are based on remembering which can be considered as a bias in the elderly [43-45].

\section{Marital status}

Another factor correlated with the prevalence of MDE in this study was the divorced status. Similarly, the French study HB found that MDE were more common among divorced (14.5\%) than widowed $(10.8 \%)$, single $(8.8 \%)$ and married $(5.9 \%)$ people. In the NEMESIS and in the ESEMeD,46 it has been found that living alone was associated with an increased risk of psychiatric disorders including depression. Results from the Canadian National Population Health Survey were in favor of a high prevalence of MDE in separated, divorced and widowed people. This difference can be explained by the existence of an increased risk of marital breakdown in patients with depression as well as a real increased risk of depression in separated people $[16,29,46,47]$.

\section{Place of residence}

The lifetime prevalence of MDE in this study was not significantly correlated with the place of residence. Several epidemiological studies have found similar results. Other studies, such as the ESEMeDand the ODIN studies, found higher prevalence of MDE in urban areas. This lower prevalence of depression in rural areas can be explained by the lack of healthcare professionals to consult for mental problems. By cons, other studies have reported a higher prevalence of MDE in rural areas, which can be due to the fact that individuals living in rural areas have more chronic diseases, lower personal resources, lower level of education and higher rates of unemployment, characteristics which are strongly associated with depression[31,48-53].

\section{Educational level}

The prevalence of MDE in this study was not correlated with the level of education of participants. Several studies have found a similar result but others have retained a positive correlation between the prevalence of MDE and a low educational level. NCS and NCS-R found that the MDE were significantly more frequent in patients with an educational level less than 12 years. This finding was also reported by Ukrainian and Brazilian studies $[9,1,12,14,15,54,55]$.

\section{Professional activity}

The prevalence of MDE in this study was not correlated with the professional activity. In contrast to this result, a positive correlation between the absence of a professional activity and the occurrence of depression was reported in the NEMESIS, [16] the ESEMeD [15] and the HB [29] studies, supporting thereby the hypothesis of a protective role of work in depression. An explanation for these findings would be that Major depressions have a negative impact on all types of activities [56] which could lead to a less professional activity. This discrepancy between these study findings and the results of our study could be explained by the fact that the CIDI allows the evaluation of the professional activity over the last 12 months while in the other studies the considered professional activity is concomitant to depression.

\section{Limitations of the Study}

The ultimate goal of this study was to have an epidemiological profile of depression in Tunisia. However, assessment concerned only patients consulting in primary care settings which may be a bias. In addition, understanding the Tunisian dialect was necessary to be included in the study while this dialect is not known by all Tunisian people and is different from one region to another. Finally, lifetime prevalence estimates are vulnerable to recall bias and can be too low if they are retrospectively assessed [57].

\section{Conclusion}

The results of this study suggest that depression is a common disorder in primary care settings in Tunisia. They also draw an epidemiological profile of the most vulnerable people to this disorder in Tunisian sociocultural context. It seems relevant and urgent to provide an appropriate training on depressive disorders to caregivers in the primary care settings in order to improve the detection and therefore the treatment of patients with depression.

\section{Conflict of interest}

The authors indicated no conflicts of interest 


\section{Acknowledgments}

This research was supported by SANOFI

\section{References}

1. Taleb M, Rouillon F, Hegerl U, Hamdani N, Gorwood P (2006) [Programmes against depression]. Encephale 32: 9-15.

2. Wittchen HU, Jacobi F (2005) Size and burden of mental disorders in Europe--a critical review and appraisal of 27 studies. Eur Neuropsychopharmacol 15: 357-376.

3. Hirschfeld RM, Keller MB, Panico S, Arons BS, Barlow D, et al. (1997) The National Depressive and Manic-Depressive Association consensus statement on the undertreatment of depression. JAMA 277: 333-340.

4. Raffaitin F, Caparros Panduro C, Biro G, Dardennes R (2011) [Depression and professional activity: results of the NEXTEP study]. Encephale 37: 59-67.

5. Lépine JP (2001) Epidemiology, burden, and disability in depression and anxiety. J Clin Psychiatry 62 Suppl 13: 4-10.

6. Caria A, Roelandt JL, Bellamy V, Vandeborre A (2010) ["Mental Health in the General Population: images and realities (MHGP)": methodology of the study]. Encephale 36: 1-6.

7. Lépine JP, Gastpar M, Mendlewicz J, Tylee A (1997) Depression in the community: the first pan-European study DEPRES (Depression Research in European Society). Int Clin Psychopharmacol 12: 19-29.

8. Andrews G, Peters L (1998) The psychometric properties of the Composite International Diagnostic Interview. Soc Psychiatry Psychiatr Epidemiol 33: 80-88.

9. Patten SB, Wang JL, Williams JV, Currie S, Beck CA, et al. (2006) Descriptive epidemiology of major depression in Canada. Can J Psychiatry 51: 84-90.

10. Fournier L, Lesage AD, Toupin J, Cyr M (1997) Telephone surveys as an alternative for estimating prevalence of mental disorders and service utilization: a Montreal catchment area study. Can J Psychiatry 42: 737-743.

11. Kessler RC, McGonagle KA, Zhao S, Nelson CB, Hughes M, et al. (1994) Lifetime and 12-month prevalence of DSM-III-R psychiatric disorders in the United States. Results from the National Comorbidity Survey. Arch Gen Psychiatry 51: 8-19.

12. Kessler RC, Berglund P, Demler O, Jin R, Koretz D, et al. (2003) The epidemiology of major depressive disorder: results from the National Comorbidity Survey Replication (NCS-R). JAMA 289: 3095-3105.

13. Canino GJ, Bird HR, Shrout PE, Rubio-Stipec M, Bravo M, et al. (1987) The prevalence of specific psychiatric disorders in Puerto Rico. Arch Gen Psychiatry 44: 727-735.

14. Almeida-Filho N1, Lessa I, Magalhães L, Araújo MJ, Aquino E, et al. (2004) Social inequality and depressive disorders in Bahia, Brazil: interactions of gender, ethnicity, and social class. Soc Sci Med 59: 1339-1353.

15. Alonso J, Angermeyer MC, Bernert S, Bruffaerts R, Brugha TS, et al. (2004) Prevalence of mental disorders in Europe: results from the European Study of the Epidemiology of Mental Disorders (ESEMeD) project. Acta Psychiatr Scand Suppl : 21-27.

16. Bij RV, Ravelli A, van Zessen G (1998) Prevalence of psychiatric disorder in the general population: results of The Netherlands Mental Health Survey and Incidence Study (NEMESIS). Soc Psychiatry Psychiatr Epidemiol 33: 587-595.

17. Kringlen E, Torgersen S, Cramer V (2001) A Norwegian psychiatric epidemiological study. Am J Psychiatry 158: 1091-1098.

18. Daradkeh TK, Ghubash R, Abou-Saleh MT (2002) Al Ain community survey of psychiatric morbidity II. Sex differences in the prevalence of depressive disorders. J Affect Disord 72: 167-176.

19. Kebede D, Alem A (1999) Major mental disorders in Addis Ababa, Ethiopia. II. Affective disorders. Acta Psychiatr Scand Suppl 397: 18-23.
20. Andrade L, Caraveo-Anduaga JJ, Berglund P, Bijl RV, De Graaf R, et al. (2003) The epidemiology of major depressive episodes: results from the International Consortium of Psychiatric Epidemiology (ICPE) Surveys. Int J Methods Psychiatr Res 12: 3-21.

21. Ansseau M, Dierick M, Buntinkx F, Cnockaert P, De Smedt J, et al. (2004) High prevalence of mental disorders in primary care. J Affect Disord 78: 49-55.

22. Tamburrino MB1, Lynch DJ, Nagel RW, Smith MK (2009) Primary care evaluation of mental disorders (PRIME-MD) screening for minor depressive disorder in primary care. Prim Care Companion J Clin Psychiatry 11: 339-343.

23. Olfson M, Shea S, Feder A, Fuentes M, Nomura Y, et al. (2000) Prevalence of anxiety, depression, and substance use disorders in an urban general medicine practice. Arch Fam Med 9: 876-883.

24. Abbo C, Ekblad S, Waako P, Okello E, Musisi S (2009) The prevalence and severity of mental illnesses handled by traditional healers in two districts in Uganda. Afr Health Sci 9 Suppl 1: S16-22.

25. Shim RS, Baltrus P, Ye J, Rust G (2011) Prevalence, treatment, and control of depressive symptoms in the United States: results from the National Health and Nutrition Examination Survey (NHANES), 2005-2008. J Am Board Fam Med 24: 33-38.

26. Sielk M, Altiner A, Janssen B, Becker N, de Pilars MP, et al. (2009) [Prevalence and diagnosis of depression in primary care. A critical comparison between PHQ-9 and GPs' judgement]. Psychiatr Prax 36: 169-174.

27. Norton J, de Roquefeuil G, David M, Boulenger JP, Ritchie K, et al. (2009) [Prevalence of psychiatric disorders in French general practice using the patient health questionnaire: comparison with GP caserecognition and psychotropic medication prescription]. Encephale 35: 560-569.

28. Gelenberg AJ (2010) The prevalence and impact of depression. J Clin Psychiatry 71: e06.

29. Lamboy B, Léon C, Guilbert P (2007) [Depressive disorders and use of health services in the French population according to the Health Barometer 2005]. Rev Epidemiol Sante Publique 55: 222-227.

30. Wilhelm K, Mitchell P, Slade T, Brownhill S, Andrews G (2003) Prevalence and correlates of DSM-IV major depression in an Australian national survey. J Affect Disord 75: 155-162.

31. Romans-Clarkson SE, Walton VA, Herbison GP, Mullen PE (1990) Psychiatric morbidity among women in urban and rural New Zealand: psycho-social correlates. Br J Psychiatry 156: 84-91.

32. Becker SM (2004) Detection of somatization and depression in primary care in Saudi Arabia. Soc Psychiatry Psychiatr Epidemiol 39: 962-966.

33. Hwu HG, Yeh EK, Chang LY (1989) Prevalence of psychiatric disorders in Taiwan defined by the Chinese Diagnostic Interview Schedule. Acta Psychiatr Scand 79: 136-147.

34. Stewart DE, Rondon M, Damiani G, Honikman J (2001) International psychosocial and systemic issues in women's mental health. Arch Womens Ment Health 4: 13-7.

35. Barrett JE, Barrett JA, Oxman TE, Gerber PD (1988) The prevalence of psychiatric disorders in a primary care practice. Arch Gen Psychiatry 45: 1100-1106.

36. Angst J, Dobler-Mikola A (1984) The Zurich study. III. Diagnosis of depression. Eur Arch Psychiatry Neurol Sci 234: 30-37.

37. Silverstein B, Edwards T, Gamma A, Ajdacic-Gross V, Rossler W, et al. (2013) The role played by depression associated with somatic symptomatology in accounting for the gender difference in the prevalence of depression. Soc Psychiatry Psychiatr Epidemiol 48: 257-263.

38. Kawakami N, Shimizu H, Haratani T, Iwata N, Kitamura T (2004) Lifetime and 6-month prevalence of DSM-III-R psychiatric disorders in an urban community in Japan. Psychiatry Res 121: 293-301.

39. Lee CK, Kwak YS, Rhee H, Kim YS, Han JH, et al. (1987) The nationwide epidemiological study of mental disorders in korea. J Korean Med Sci 2: 19-34. 
Citation: Bannour AS, Krir MW, Braham A, Ben Nasr S, Ben Hadj Ali B (2015) The Lifetime Prevalence and Socio-Demographic Correlations of Major Depressive Episodes in Tunisian Primary Care Settings. J Psychiatry 18: 225. doi:10.4172/2378-5756.1000225

Page 6 of 6

40. Copeland JR, Dewey ME, Wood N, Searle R, Davidson IA, et al. (1987) Range of mental illness among the elderly in the community. Prevalence in Liverpool using the GMS-AGECAT package. Br J Psychiatry 150: 815-823.

41. Menchetti M, Cevenini N, De Ronchi D, Quartesan R, Berardi D (2006) Depression and frequent attendance in elderly primary care patients. Gen Hosp Psychiatry 28: 119-124.

42. Solhaug HI, Romuld EB, Romild U, Stordal E (2012) Increased prevalence of depression in cohorts of the elderly: an 11-year follow-up in the general population - the HUNT study. Int Psychogeriatr 24: 151-158.

43. Eaton WW, Holzer CE 3rd, Von Korff M, Anthony JC, Helzer JE, et al. (1984) The design of the Epidemiologic Catchment Area surveys. The control and measurement of error. Arch Gen Psychiatry 41: 942-948.

44. Rothermund K, Brandtstädter J (2003) Depression in later life: crosssequential patterns and possible determinants. Psychol Aging 18: 80-90.

45. Hoertel N, Le Strat Y, Gorwood P, Bera-Potelle C, Schuster JP, et al. (2013) Why does the lifetime prevalence of major depressive disorder in the elderly appear to be lower than in younger adults? Results from a national representative sample. J Affect Disord 149: 160-5.

46. Lépine JP, Gasquet I, Kovess V, Arbabzadeh-Bouchez S, Nègre-Pagès L, et al. (2005) Prévalence et comorbidité des troubles psychiatriques dans la population générale française : résultats de l'étude épidémiologique ESEMeD/MHEDEA 2000/ (ESEMeD). Encephale 31: 182-94.

47. Bulloch AG, Williams JV, Lavorato DH, Patten SB (2009) The relationship between major depression and marital disruption is bidirectional. Depress Anxiety 26: 1172-1177.

48. Blazer DG, Kessler RC, McGonagle KA, Swartz MS (1994) The prevalence and distribution of major depression in a national community sample: the National Comorbidity Survey. Am J Psychiatry 151: 979-986.
49. Parikh SV, Wasylenki D, Goering P, Wong J (1996) Mood disorders: rural/urban differences in prevalence, health care utilization, and disability in Ontario. J Affect Disord 38: 57-65.

50. Kovess-Masféty V, Alonso J, de Graaf R, Demyttenaere K (2005) A European approach to rural-urban differences in mental health: the ESEMeD 2000 comparative study. Can J Psychiatry 50: 926-936.

51. Ayuso-Mateos JL, Vázquez-Barquero JL, Dowrick C, Lehtinen V, Dalgard OS, et al. (2001) Depressive disorders in Europe: prevalence figures from the ODIN study. Br J Psychiatry 179: 308-316.

52. Probst JC, Laditka SB, Moore CG, Harun N, Powell MP, et al. (2006) Rural-urban differences in depression prevalence: implications for family medicine. Fam Med 38: 653-660.

53. Auchincloss AH1, Hadden W (2002) The health effects of rural-urban residence and concentrated poverty. J Rural Health 18: 319-336.

54. Lindeman S, Hämäläinen J, Isometsä E, Kaprio J, Poikolainen K, et al. (2000) The 12-month prevalence and risk factors for major depressive episode in Finland: representative sample of 5993 adults. Acta Psychiatr Scand 102: 178-184.

55. Bromet EJ, Gluzman SF, Paniotto VI, Webb CP, Tintle NL, et al. (2005) Epidemiology of psychiatric and alcohol disorders in Ukraine: findings from the Ukraine World Mental Health survey. Soc Psychiatry Psychiatr Epidemiol 40: 681-690.

56. Breslin FC, Gnam W, Franche RL, Mustard C, Lin E (2006) Depression and activity limitations: examining gender differences in the general population. Soc Psychiatry Psychiatr Epidemiol 41: 648-655.

57. Patten SB (2009) Accumulation of major depressive episodes over time in a prospective study indicates that retrospectively assessed lifetime prevalence estimates are too low. BMC psychiatry 9:19. 